\title{
Visualizing the mobility of silver during catalytic soot oxidation
}

Gardini, Diego; Christensen, Jakob M.; Damsgaard, Christian Danvad; Jensen, Anker D.; Wagner, Jakob B.

Published in:

Applied Catalysis B: Environmental

Link to article, DOI:

10.1016/j.apcatb.2015.10.029

Publication date:

2016

Document Version

Peer reviewed version

Link back to DTU Orbit

Citation (APA):

Gardini, D., Christensen, J. M., Damsgaard, C. D., Jensen, A. D., \& Wagner, J. B. (2016). Visualizing the mobility of silver during catalytic soot oxidation. Applied Catalysis B: Environmental, 183, 28-36.

https://doi.org/10.1016/j.apcatb.2015.10.029

\section{General rights}

Copyright and moral rights for the publications made accessible in the public portal are retained by the authors and/or other copyright owners and it is a condition of accessing publications that users recognise and abide by the legal requirements associated with these rights.

- Users may download and print one copy of any publication from the public portal for the purpose of private study or research.

- You may not further distribute the material or use it for any profit-making activity or commercial gain

- You may freely distribute the URL identifying the publication in the public portal 


\title{
Visualizing the Mobility of Silver During Catalytic Soot Oxidation
}

Diego Gardini $^{1}$, Jakob M. Christensen ${ }^{2}$, Christian D. Damsgaard ${ }^{1,3}$, Anker D. Jensen ${ }^{2}$, Jakob B. Wagner $^{1 *}$

${ }^{1}$ Center for Electron Nanoscopy, Technical University of Denmark, Fysikvej, Building 307, DK2800 Kgs. Lyngby, Denmark.

${ }^{2}$ Department of Chemical and Biochemical Engineering, Technical University of Denmark, Søltofts Plads, Building 229, DK-2800 Kgs. Lyngby, Denmark

${ }^{3}$ Center for Individual Nanoparticle Functionality, Department of Physics, Technical University of Denmark, Fysikvej, Building 307, DK-2800 Kgs. Lyngby, Denmark

\begin{abstract}
The catalytic activity and mobility of silver nanoparticles used as catalysts in temperature programmed oxidation of soot:silver (1:5 wt:wt) mixtures have been investigated by means of flow reactor experiments and in situ environmental transmission electron microscopy (ETEM). The carbon oxidation temperature was significantly lower compared to uncatalyzed soot oxidation with soot and silver loosely stirred together (loose contact) and lowered further with the two components crushed together (tight contact). The in situ TEM investigations revealed that the silver particles exhibited significant mobility during the soot oxidation, and this mobility, which increases the soot/catalyst contact, is expected to be an important factor for the lower oxidation temperature. In the intimate tight contact mixture the initial dispersion of the silver particles is greater, and the onset of mobility occurs at a lower temperature which is consistent with the lower oxidation temperature of the tight contact mixture.
\end{abstract}

Keywords: silver mobility, environmental TEM, soot oxidation

\section{Introduction}

Soot particles in the exhaust from diesel vehicles are likely to cause lung cancer and to affect the local climate and air quality [1-6]. For that reason the soot particles are typically removed from the exhaust

Corresponding author. Tel: +4545256471. E-mail: jakob.wagner@cen.dtu.dk 
gas by filtration through a ceramic filter $[7,8]$. The filter needs periodic regeneration, in which the filter temperature is increased, and the soot is burned away. The growing back pressure due to the soot deposits and the increased temperature required for filter regeneration increase the fuel consumption $[9,10]$. To limit this extra fuel consumption it is desirable to develop low temperature soot oxidation catalysts to lower the regeneration temperature. The heterogeneously catalyzed soot oxidation is a gas/solid/solid interaction, and the contact between soot and catalyst is very important for the catalytic activity [11]. In tests where soot and catalyst are crushed together (so-called tight contact), the oxidation occurs at a significantly lower temperature, compared to when soot and catalyst are stirred together with a spatula (so-called loose contact) [11]. Several experiments with diesel soot filters [10, 12-15] have indicated the presence of both contact types. An explanation of this may come from the environmental scanning electron microscopy experiments by Kameya and Lee [16], who observed that the catalytic oxidation at the interface between the bottom of the soot cake and the catalyst containing filter caused the soot cake to crack, leading to a delamination and subsequent diminishment or even loss of soot/catalyst contact [16]. It is thus likely that the development of catalysts for real filter applications will benefit from an understanding of both types of contact.

In terms of what constitutes a good catalyst both the surface area [17-19] and the strength of the oxygen-catalyst bond are very important for the catalytic activity [20]. Silver is able to activate oxygen by dissociative adsorption already at low temperature [21, 22], and in a number of cases silver-based catalysts have been reported to exhibit high activity for catalytic soot oxidation [18, 2333]. It is particularly interesting that soot oxidation at relatively low temperatures has been achieved in loose contact with silver [24,33]. It is therefore relevant to investigate the behavior of silver at the conditions of catalytic soot oxidation. In this work we employ catalytic oxidation tests and environmental transmission electron microscopy (ETEM) during in situ soot oxidation to evaluate the behavior of silver at the conditions relevant for catalytic soot oxidation. ETEM is a unique tool for visualizing and characterizing the dynamic evolution of soot oxidation catalysts in action as illustrated by earlier works $[34,35]$.

\section{Experimental}

\subsection{Materials}


A commercial Ag nanopowder sample from Sigma-Aldrich $\left(2.1 \mathrm{~m}^{2} / \mathrm{g},<932 \mathrm{ppm}\right.$ metal impurities, $\sim 2 \mathrm{wt} \%$ PVP) was used as catalyst in the experiments. The identity of the silver sample was verified by X-Ray diffraction (Figure S1 in the Supplementary Information). The soot used in the experiments was a reference material from NIST: "SRM 2975 Diesel Particulate Matter" (91 m²/g, 86-87 wt\% C, 1-2 wt\% H, 1 wt\% S, $2.7 \mathrm{wt} \%$ extractable organics [19, 34-36]).

\subsection{Catalyst characterization}

Morphology, chemical composition and crystallinity of silver and soot were investigated with a FEI Titan 80-300 Analytical transmission electron microscope (TEM) operated at $300 \mathrm{kV}$ in brightfield (BF) and high-angle annular dark field (HAADF) scanning TEM (STEM) mode. The soot:silver mixtures were dry dispersed onto lacey carbon supported copper grids and loaded on a standard single tilt TEM holder.

\subsection{Catalytic soot oxidation in flow reactor}

The catalytic activity of Ag in soot oxidation was measured using temperature programmed oxidation (TPO) in a flow reactor setup described elsewhere [20]. For the activity tests soot ( $2 \mathrm{mg})$ and catalyst in a ratio of 1:5 (wt:wt) were stirred together with a spatula (loose contact) or crushed together for 6 minutes in an agate mortar (tight contact). The soot/catalyst mixture was transferred to a $7 \mathrm{~cm}$ long, $1 \mathrm{~cm}$ wide alumina sample holder, which was placed in the center of a quartz tube (length: $65 \mathrm{~cm}$, inner diameter: $24 \mathrm{~mm}$ ) within a horizontal, tubular furnace. The sample was then subjected to a 1 $\mathrm{NL} /$ min flow of 10.2 vol\% $\mathrm{O}_{2}$ in $\mathrm{N}_{2}$. The feed gases $\left(\mathrm{N}_{2}\right.$ and $\mathrm{O}_{2}$ from AGA A/S $)$ were dosed by means of Bronkhorst EL-FLOW mass flow controllers. When the sample had been installed in the oven, and once any remnants of air had been purged from the reactor (when the $\mathrm{CO}_{2}$ signal from ambient air had dropped below the detection limit) the reactor was heated at a rate of $11{ }^{\circ} \mathrm{C} / \mathrm{min}$ to a final temperature of $750{ }^{\circ} \mathrm{C}$. The temperature was monitored by a type $\mathrm{K}$ thermoelement at the external surface of the quartz tube wall. The concentrations of $\mathrm{CO}$ and $\mathrm{CO}_{2}$ in the reactor effluent were monitored continuously using an ABB AO2020 IR gas analyzer calibrated using a certified $\mathrm{CO} / \mathrm{CO}_{2} / \mathrm{N}_{2}$ gas mixture from AGA A/S. During the experiments the levels of $\mathrm{CO}$ and $\mathrm{CO}_{2}$ in the effluent stream were in the 0-500 ppmv range, and the oxygen conversion was thus negligible in the 
present experiments. In one experiment the supply of pure oxygen was replaced with a $1 \mathrm{vol} \% \mathrm{O}_{2}$ in $\mathrm{N}_{2}$ gas mixture (AGA A/S) to obtain an oxygen partial pressure (296 Pa) almost identical to the one employed in the ETEM experiments.

\subsection{In situ soot oxidation in the environmental transmission electron microscope}

In situ soot oxidation was investigated in a FEI Titan 80-300 transmission electron microscope equipped with a differentially pumped environmental cell [37]. The soot:silver mixtures (1:5 wt:wt) in loose and tight contact mode were dry dispersed on the surface of MEMS thermal EMheaterchips (DENSsolutions) with no carbon support film and then mounted in an SH30 heating holder (DENSsolutions). In the electron microscope, the samples were exposed to $300 \mathrm{~Pa} \mathrm{O}_{2}$ and heated in the temperature range $150-854{ }^{\circ} \mathrm{C}$ at a rate of $11^{\circ} \mathrm{C} / \mathrm{min}$.

\section{Results and Discussion}

\subsection{Soot/catalyst contact}

The bright field TEM (BF-TEM) micrographs of soot:silver mixtures (1:5 wt:wt) in Figure,1Figure1 illustrate the contact between the solids in the two contact conditions. In loose contact silver was observed to form big agglomerates sharing a limited number of contact points with the soot agglomerates. In tight contact silver particles were instead observed to be more dispersed, and most of the surface of the catalyst appears to interface the soot. 

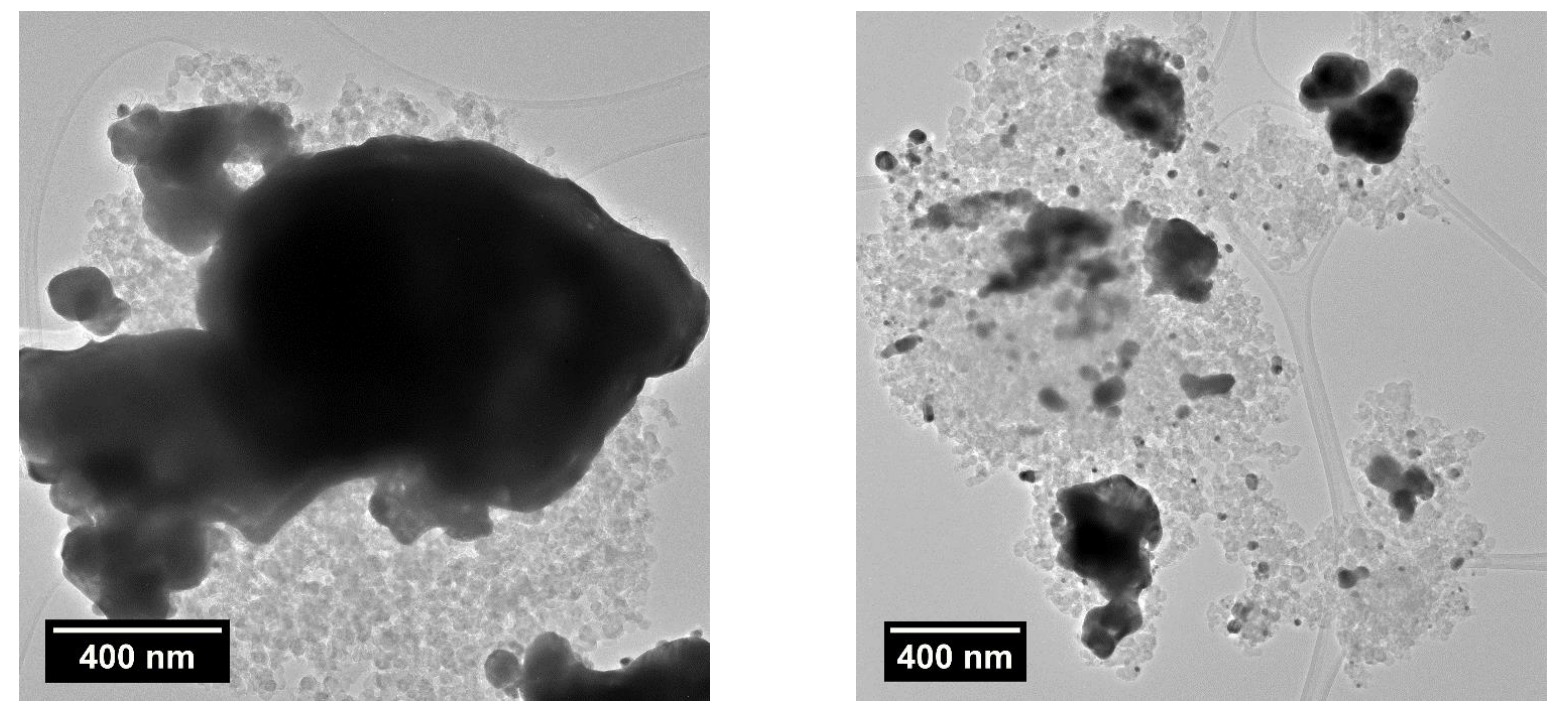

Figure 1 Bright Field TEM micrograph of a soot:silver (1:5 wt:wt) mixture in (left) loose contact and (right) tight contact condition. Darker agglomerates represent the silver fraction of the specimen while the lighter porous structure is the soot. In both micrographs a portion of the lacey carbon support holding the specimen is visible.

Scanning Transmission Electron Microscopy (STEM) analysis of the two samples revealed the presence of a distribution of small nanoparticles of approximately 2-5 $\mathrm{nm}$ diameter in both contact modes (cf. Figure 2Figure 2). These were mostly identified in the near vicinity of big silver clusters, but were found as well mixed with the soot cake far from the main Ag agglomerates. STEM Energy Dispersive X-Ray Spectroscopy (STEM-EDX) measurements carried out on a single small nanoparticle (cf. Figure 3Figure 3-a) and on areas containing few particles (cf. Figure 3Figure 3-b) revealed in both cases the presence of the elements silver, carbon and sulfur. The presence of carbon and sulfur were ascribed to the soot fraction [34]. The small nanoparticles identified by STEM might represent a finely divided fraction of the silver catalyst. The copper signal in the spectrum originated from the sample holder, and the observed sodium might be a part of the ash in the soot. 

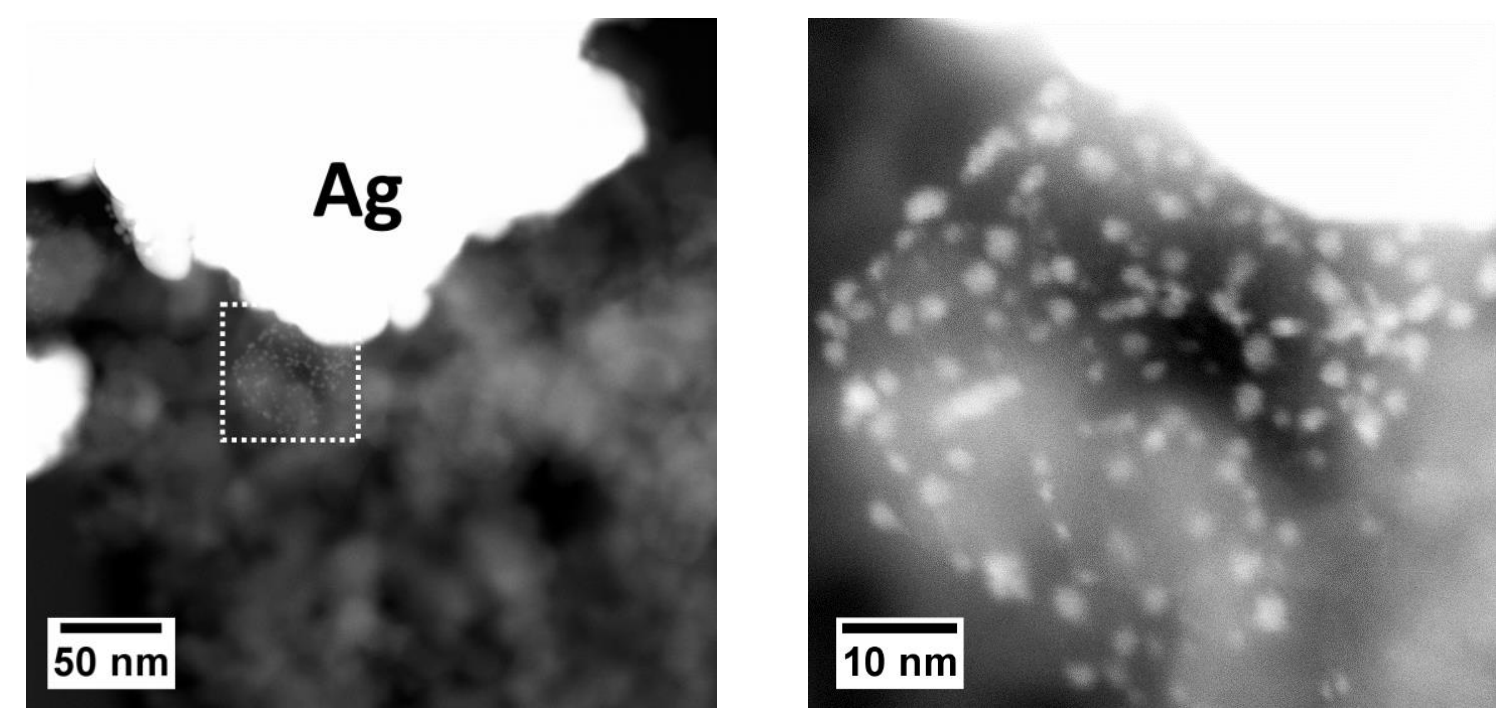

Figure 2 (Left) STEM micrograph of a soot:silver (1:5 wt:wt) mixture in loose contact mode. A group of small nanoparticles (bright spots in the white box) close to a silver agglomerate is highlighted. (Right) Close-up on the particle area. Contrast has been enhanced in order to better visualize the soot underlying the catalyst.
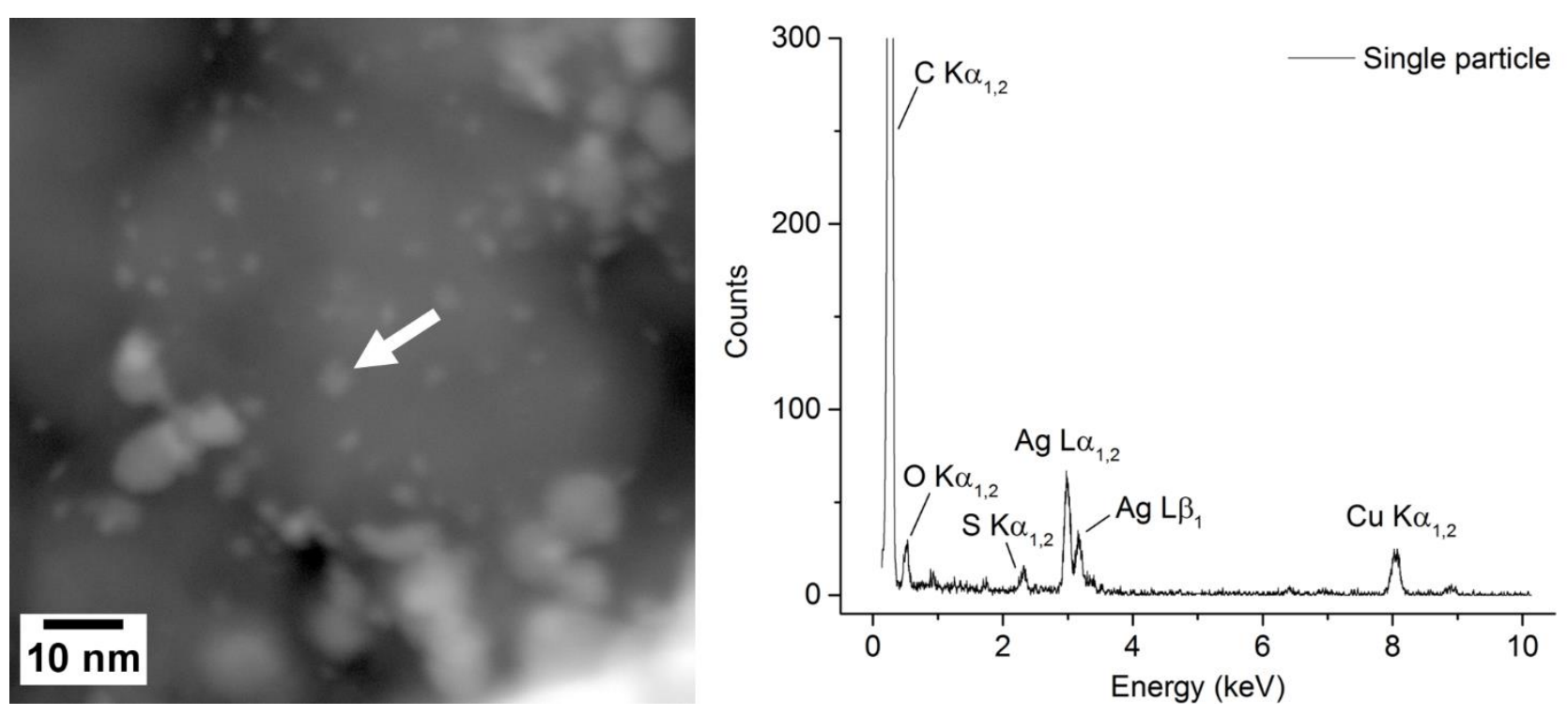

(a) Single particle analysis 

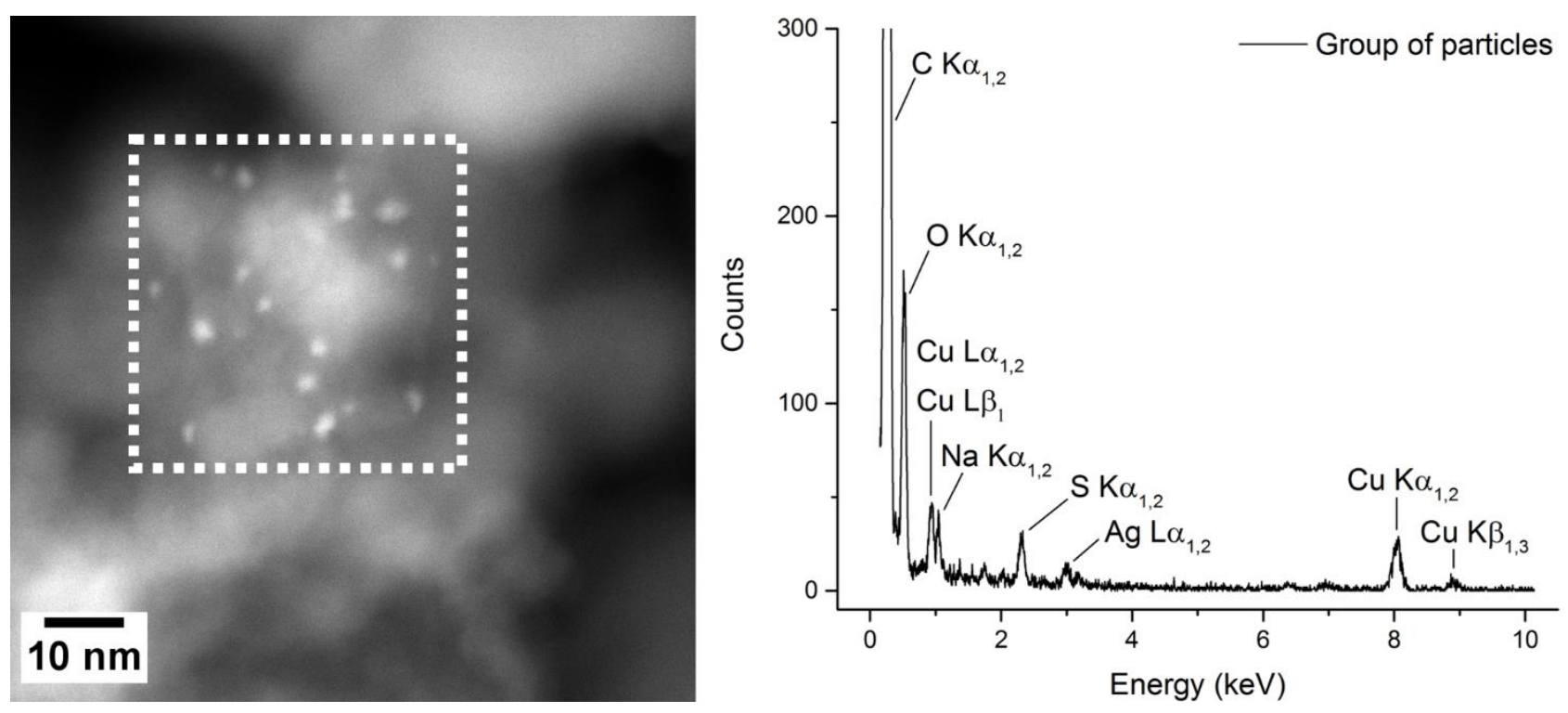

\section{(b) Group particles analysis}

Figure 3 STEM micrograph (left) and STEM-EDX spectrum (right) of (a) a silver single particle and (b) a group of silver particles. Graphical elements in white indicate the origin of the EDX signal on the sample.

\subsection{Activity in catalytic oxidation}

Figure 4Figure 4 shows the oxidation rate as a function of temperature for pure soot, and for soot mixed with Ag in tight or loose contact in the flow reactor tests. The silver catalyst generally shows a high activity for soot oxidation. The significant activity in loose contact, where the temperature of maximal oxidation rate is shifted downwards by $123{ }^{\circ} \mathrm{C}$ compared to pure soot, is especially noteworthy, since it is very challenging to achieve a significant activity in this situation $[11,20]$. The reason for the high activity in loose contact will be discussed further in section 3.4 below. The sharp peak in the oxidation rate at a temperature of $325^{\circ} \mathrm{C}$ is due to oxidation of polyvinylpyrrolidone (PVP), which is present as as a stabilizer/dispersant in the commercial silver nanoparticle sample. Figure S2 in the Supplementary information shows how the oxidation of this polymer in the absence of soot occurs in a sharp peak just above $300{ }^{\circ} \mathrm{C}$ (see also Shen et al. [38]). In a rerun experiment, where the spent silver sample is again mixed with soot in loose contact, the activity is decreased, however despite having been exposed to high temperature the silver catalyst retains significant activity for loose contact soot oxidation (“Loose contact rerun” in Figure 4Figure 4). 


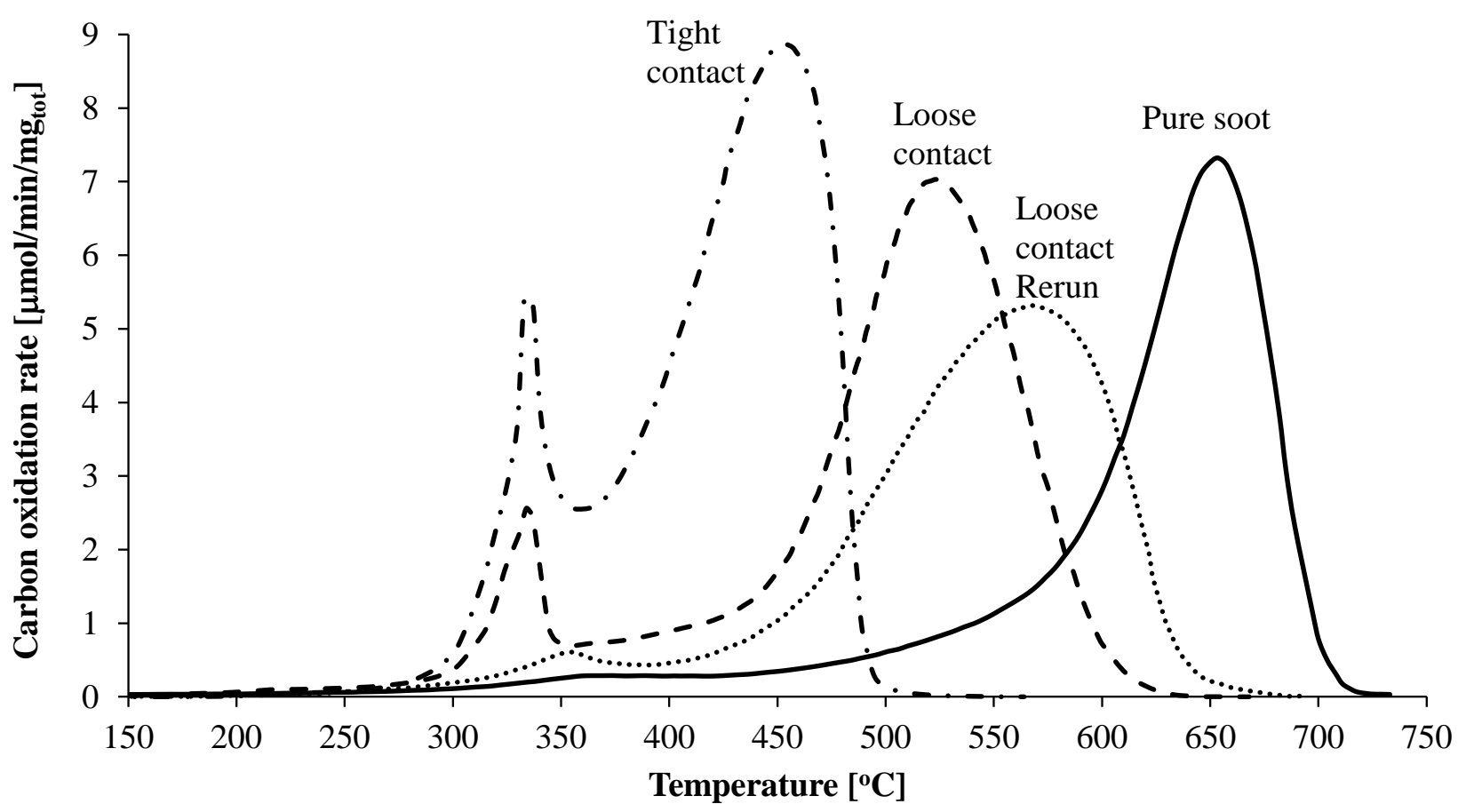

Figure 4 The rate of carbon oxidation (normalized by the total, initial mass of carbon) during TPO experiments with silver catalyzed soot oxidation. Experimental conditions: soot:silver $=1: 5$ wt:wt, ramp $=11^{\circ} \mathrm{C} / \mathrm{min}, 1 \mathrm{NL} / \mathrm{min}, 10.2 \mathrm{vol} \% \mathrm{O}_{2}$ in $\mathrm{N}_{2}$.

\subsection{In situ soot oxidation in the environmental transmission electron microscope}

It is known $[11,20]$ to be a great challenge to achieve a significant lowering of the oxidation temperature with loose contact between catalyst and soot, and the significant effect of metallic silver in loose contact with soot is thus a particularly striking feature in Figure 4Figure 4. Assuming an intermediate oxygen coverage the heat of oxygen chemisorption on metallic silver should be in the order of $130 \mathrm{~kJ} / \mathrm{mol}$ [39-41], which should make silver well suited for oxygen activation [20, 42]. However there might also be behavioral traits that contribute towards enabling silver to achieve soot oxidation at relatively low temperatures. In order to improve the understanding of the catalytic behavior of metallic silver, soot:silver mixitures in both tight and loose contact conditions were investigated using environmental transmission electron microscopy (ETEM). In situ oxidation was carried out in an oxygen partial pressure $p_{\mathrm{O}_{2}}=300 \mathrm{~Pa}$ by heating the mixtures from 150 to $854{ }^{\circ} \mathrm{C}$ using the same temperature ramp as in the flow reactor experiments $\left(11^{\circ} \mathrm{C} / \mathrm{min}\right)$. Micrographs of the 
oxidation reaction are acquired every 25 seconds and finally combined together to form playable time-lapses of 8 FPS (Movie 1 and 2) and 10 FPS (Movie 3).

\section{In situ oxidation in loose contact}

Figure 5Figure 5 shows four key frames representing soot oxidation in the ETEM in the loose contact condition. As Movie 1 shows, in the temperature range $25-280{ }^{\circ} \mathrm{C}$ no evident changes in soot or $\mathrm{Ag}$ morphology were observed (Figure 5Figure 5-a). As the temperature increased from 280 to $472{ }^{\circ} \mathrm{C}$, silver particles began to coalesce, forming larger rounded agglomerates (Figure 5Figure 5-b). At 500 ${ }^{\circ} \mathrm{C}$ coalesced silver agglomerates were observed to be mobile, moving on the soot cake and actively oxidizing the soot particles. Soot oxidation at the $\mathrm{Ag} / \mathrm{C}$ interface was visually confirmed by the disappearance of soot particles in contact with silver. The mobility was estimated visually to be maximal around $700{ }^{\circ} \mathrm{C}$ (Figure 5Figure 5-c) and oxidation was reported to end at about $760{ }^{\circ} \mathrm{C}$, when all the soot was consumed and the silver had coalesced to a single particle (Figure 5Figure 5d). 


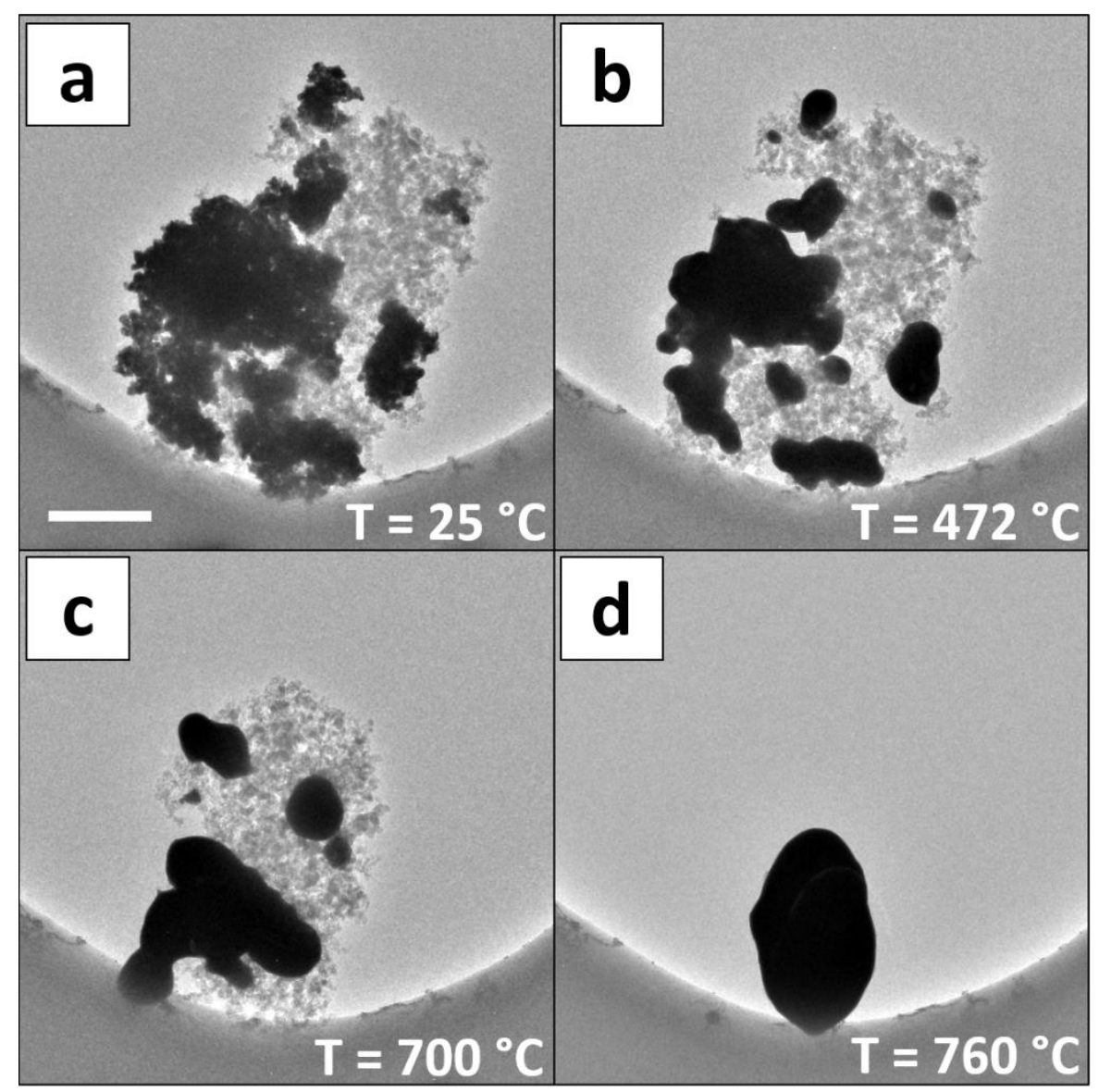

Figure 5 BF-TEM micrographs of in situ soot oxidation in the ETEM in loose contact condition showing (a) initial distribution and morphology of silver and soot, (b) coalescence of silver particles, (c) mobility of coalesced silver agglomerates over the soot cake and (d) final silver agglomeration. Scalebar is $500 \mathrm{~nm}$.

In situ oxidation in tight contact

Similarly to what has been presented in the previous paragraph for loose contact, the four steps of in situ soot oxidation in the tight contact condition are summarized in Figure 6Figure 6. As Movie 2 shows, in the temperature range $25-250{ }^{\circ} \mathrm{C}$ no obvious changes in soot or $\mathrm{Ag}$ morphology were observed except for the collapse of part of the soot structure on the right hand side of the specimen area (Figure 6Figure 6-a). Between 250 and $338^{\circ} \mathrm{C}$ silver particles coalesced forming round agglomerates (Figure 6Figure 6-b). Silver coalescence was observed to occur approximately $30{ }^{\circ} \mathrm{C}$ earlier compared to the loose contact condition due to the presence of smaller silver particles in the sample- naturally requiring lower temperatures for initiating the coalescence process. Starting from $\mathrm{T}=342{ }^{\circ} \mathrm{C}$ the small silver particle groups exhibited high mobility over the soot cake. Oxidation 
activity by silver particles could again be identified by disappearance of soot. Silver mobility was estimated to have its peak around $526{ }^{\circ} \mathrm{C}$ (Figure 6Figure 6-c). Around $700{ }^{\circ} \mathrm{C}$ soot oxidation was

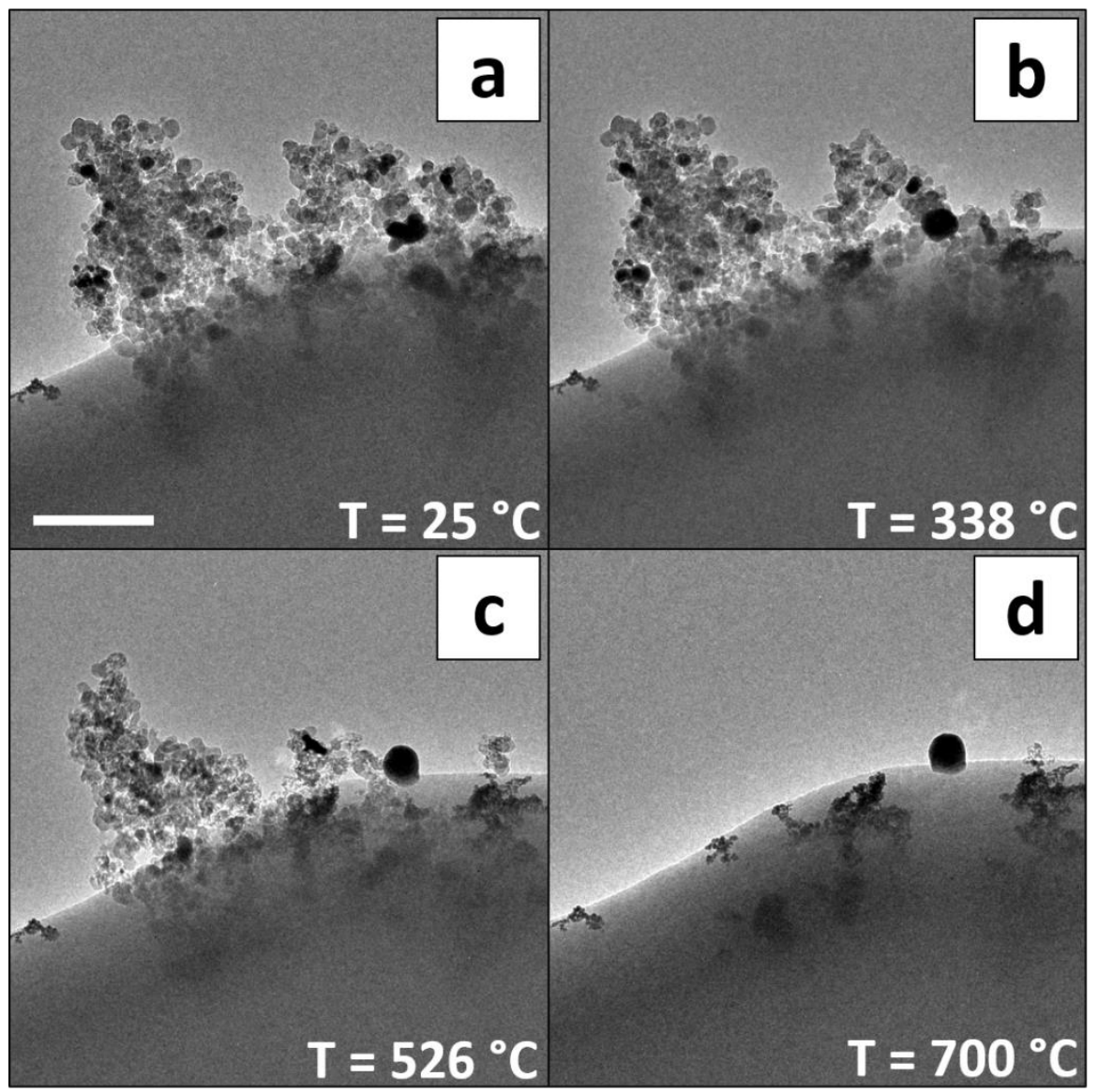

Figure 6 BF-TEM micrographs of in situ soot oxidation in the ETEM in tight contact condition showing (a) initial distribution and morphology of silver and soot, (b) coalescence of silver particles, (c) mobility of coalesced silver agglomerates over the soot cake and (d) final silver agglomeration. Scalebar is $300 \mathrm{~nm}$.

\subsection{Origin of silver mobility and its implications on catalytic activity}

Previous studies in literature have shown that the oxidation of graphite single crystals can be effectively catalyzed by a two-step mechanism involving the mobility of metallic nanoparticles [43, 44]. At $500{ }^{\circ} \mathrm{C}$ in a $670 \mathrm{~Pa} \mathrm{O}_{2}$ atmosphere, platinum nanoparticles were reported to initially penetrate the graphite basal plane to produce pits. Upon temperature increase to $735^{\circ} \mathrm{C}$ the particles 
were found to move parallel to the graphite surface, digging relatively straight channels with sudden change of direction by 60 and $120^{\circ}$ [43]. In a similar experiment, between $327-577^{\circ} \mathrm{C}$ and in an atmosphere of $4.5-13 \mathrm{~Pa} \mathrm{O}_{2}$, silver nanoparticles deposited on graphene were reported to catalytically remove carbon atoms producing channels aligned parallel to the $\langle 100\rangle$ graphene directions [45]. This channeling effect could be explained by taking the adhesion energy between the metal particle and the carbon edge atoms in contact with it into consideration. This adhesion has been ascribed to van der Waal forces at the metal/carbon interface [44], although chemical bonding cannot be completely excluded. In DFT calculations Pizzocchero et al. [46] did observe a bonding between the edge of graphene and silver. During oxidation, the temperature is high enough to enhance the mobility of silver atoms and cause wetting of the graphite surface. As carbon atoms are removed by catalytic oxidation these attractive forces at the interface pull the silver particle along with the reaction front causing the particle to move. The straightness and preferential orientation of the channels would then arise from the anisotropic reactivity of the oxidation reaction along different lattice directions, as seen in both graphite and graphene oxidation where channels were found to be oriented parallel to the $\langle 100\rangle$ directions. Silver particle motion on an amorphous and tridimensional structure like soot is not expected to follow any preferential direction, but rather to reflect the local variations of the Ag-C interface due to soot morphology. As shown in Section 3.3 and summarized in Table 1 the onset of silver mobility and the mobility peak temperatures remain very dependent on the initial contact, although silver was found to start coalescing at approximately the same temperature for both loose and tight contact. The presence of PVP might have an influence on the initial silver coalescence. Oxidation of the PVP stabilizer layer is most likely needed before Ag nanoparticles start to coalesce. This may justify the similar temperature needed to trigger this sintering process for both contact modes.

Table 1 Temperature (in ${ }^{\circ} \mathrm{C}$ ) onsets and ranges for coalescence, mobility onset, maximal mobility and end of oxidation as observed from ETEM experiments.

\section{Loose contact}

\begin{tabular}{ccc}
\hline Coalescence & $280-472$ & $250-338$ \\
Mobility onset & 500 & 342 \\
Maximal mobility & 700 & 526 \\
End of oxidation & 760 & 700
\end{tabular}


Overall, mobility of silver in the tight contact condition was found to occur at consistently lower temperature than in the loose contact condition. As Movie 3 shows, in loose contact, silver particles in larger clusters are kept together by the Ag-Ag cohesive energy from large agglomerates in contact with the soot cake (cf. Figure 7Figure 7-a). Upon temperature increase, silver particles start to coalesce forming round agglomerates (cf. Figure 7Figure 7-b). Silver was observed to maintain its crystalline state after coalescence phase and throughout the rest of the in situ oxidation experiment for both contact modes. This was confirmed by the report of typical BF-TEM diffraction halos from silver particles and the acquisition of time lapsed electron diffraction patterns during additional in situ oxidation experiments (cf. Figure S3 in Supplementary Information). As the temperature rises, silver layers situated at the edge of the coalesced agglomerates have sufficient energy to overcome the internal Ag-Ag cohesive energy and start wetting the soot surface causing a local deformation of the agglomerate (cf. Figure 7Figure 7-c). When the temperature is high enough, catalytic carbon oxidation occurs and the attractive forces between silver and soot will maintain the contact between silver and the progressing oxidation front, causing a net movement of the Ag agglomerate (cf. Figure 7Figure 7-d). The local geometry of the silver/soot interface can greatly influence the magnitude of the attractive forces. In extreme cases, wetting can cause portions of silver agglomerates to deform to the point where separation occurs and smaller silver particles released from the main Ag agglomerate start to move on the soot cake (cf. Figure 8Figure 8).

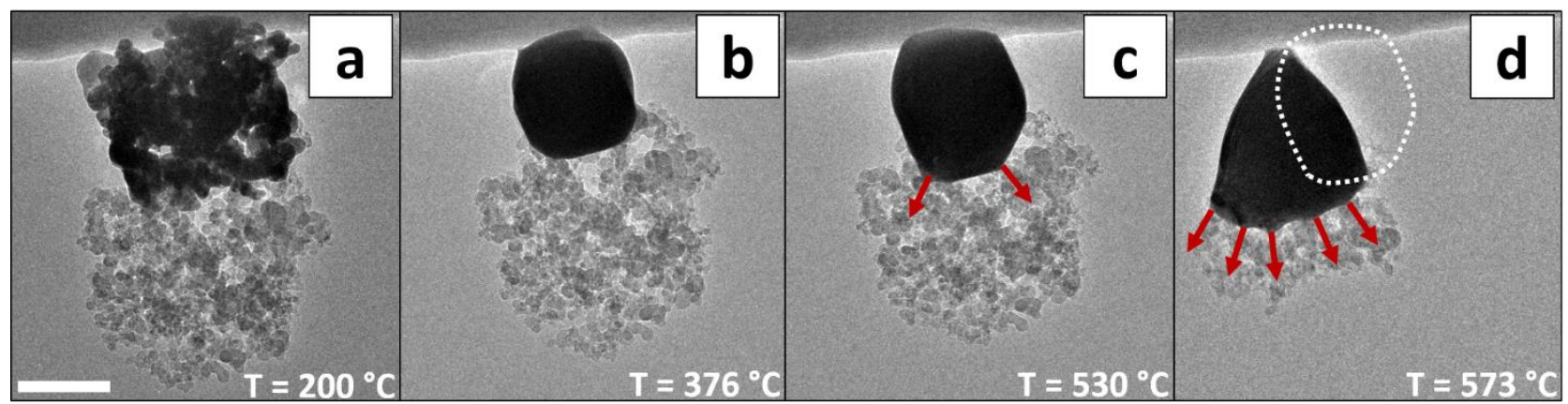

Figure 7 Wetting and movement of a silver agglomerate during in situ oxidation of soot:silver mixture in loose contact condition. BF-TEM micrographs shows (a) initial agglomeration and morphology of silver and soot, (b) coalescence of silver particles, (c) initial deformation of coalesced silver agglomerate due to capillary forces and (d) movement of silver agglomerate. Arrows in red indicate the direction of deformation of the silver agglomerate. The previous 
position of the silver agglomerate as observed in (c) is highlighted in subfigure (d) with a dashed white line. Scalebar is $200 \mathrm{~nm}$.

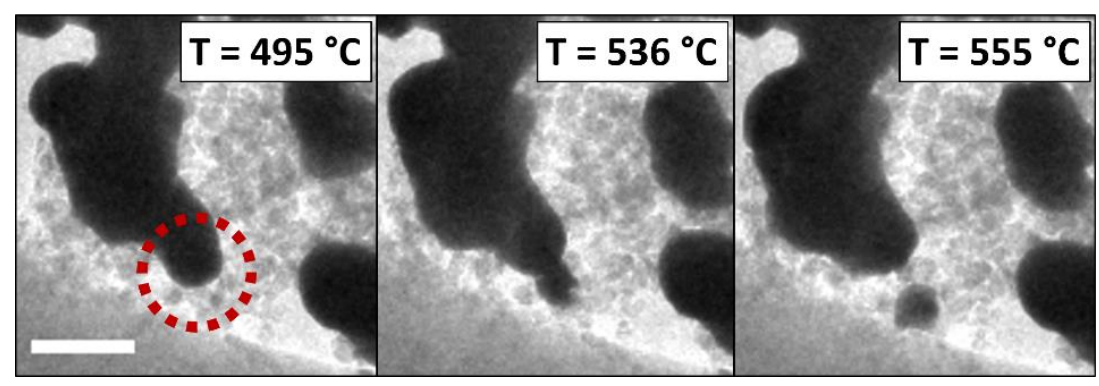

Figure 8 BF-TEM micrographs showing the detachment of a small portion of silver from a bigger agglomerate during in situ oxidation of soot:silver mixture in loose contact condition. The red dashed ring indicates the region where detachment occurs. Scalebar is $200 \mathrm{~nm}$.

It thus seems reasonable that silver exhibits a relatively high loose contact activity, as the relatively high mobility of the silver helps to overcome the initially poor dispersion of the catalyst particles in loose contact.

In the case of tight contact, where the oxidation occurs at a lower temperature, the silver is present as smaller agglomerates (or isolated silver particles), and not only is the carbon/silver interface greater than in the loose contact case, but the mobility of an isolated silver particle is also not restricted by the same Ag-Ag cohesive energy as a silver particle within a larger cluster. It is hence reasonable that the tight contact mixture exhibits mobility at lower temperatures compared to loose contact in complete consistency with the lower oxidation temperature. A clear example of this mobility behavior is further shown in Movie 3, where small $(<10 \mathrm{~nm})$ silver nanoparticles dispersed on the soot fraction were observed to be mobile at lower temperatures than the large silver agglomerate (c.f. Figure 9Figure 9). 


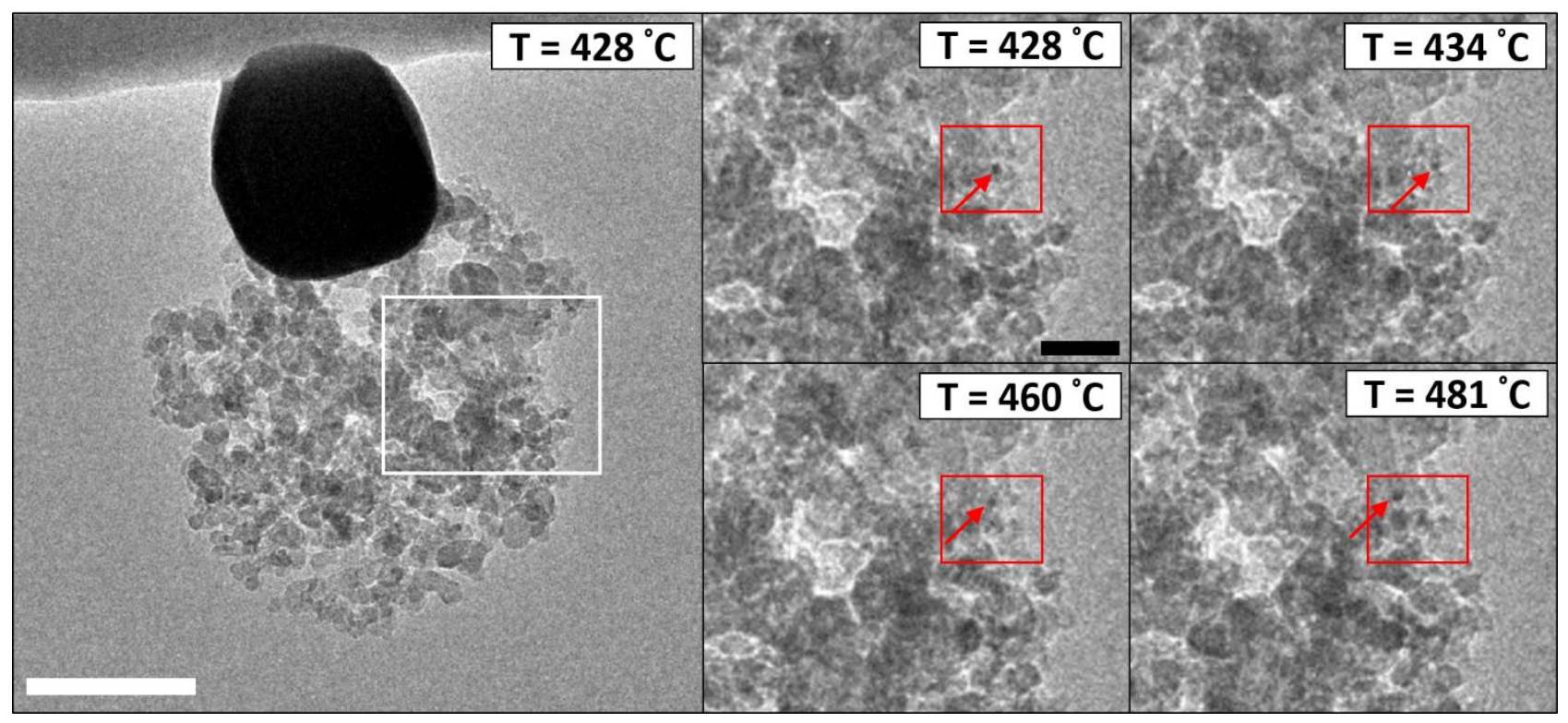

Figure 9 Mobility of small $(<10 \mathrm{~nm})$ silver particles during in situ oxidation of a soot:silver mixture in loose contact condition. The area highlighted in the white rectangle is magnified in the subfigures on the right. Scalebar in the main figure is $200 \mathrm{~nm}$. Scalebar in the subfigures is 50 $\mathrm{nm}$. The position of the red rectangle is fixed and can be used as a reference for the eye in order to track the movement of the silver particle.

Ag mobility thus plays a key role in the catalyzed oxidation of soot by constantly ensuring the presence of a silver-carbon-oxygen reactive interface. This reciprocal relationship between oxidation and mobility was verified in an in situ control experiment, wherein a soot:silver mixture in tight contact mode did not show any mobility effect when heated in absence of oxygen (vacuum), thus confirming that soot oxidation is necessary for mobility to take place (cf. Figure S4 in Supplementary Information).

\subsection{Effects of oxygen pressure}

The oxidation temperature differences observed in the flow reactor experiments for soot:silver mixtures in loose and tight contact conditions (cf. Section 3.3, Table 2), could then be ascribed to the different temperatures required to trigger the mobility of silver for the two different contact conditions. In tight contact, small silver particles requires lower temperatures to start moving and actively oxidize the soot cake while being moved by attractive forces, possibly van der Waal forces. 
Vice-versa, in loose contact, higher temperatures are needed in order for van der Waal forces to overcome the silver agglomerate's internal Ag-Ag cohesive energy and initiate oxidative mobility.

Table 2 Peak and ending temperatures (in ${ }^{\circ} \mathrm{C}$ ) of soot oxidation as observed from activity measurements (Section 3.3).

\begin{tabular}{rcc} 
& Loose contact & Tight contact \\
\hline Carbon oxidation rate peak & 520 & 440 \\
End of oxidation & 625 & 500
\end{tabular}

In this case the ETEM experiments at a comparatively low oxygen pressure are used to explain the behavior in the flow reactor tests with a partial pressure representative for real diesel vehicle exhaust, and the pressure gap should thus be taken into account. For both loose and tight contact conditions the temperature offset between overall silver mobility as observed in ETEM experiments and carbon oxidation rate from TPO experiments could be related to the different oxygen pressures used in the two setups. If it is assumed that the soot oxidation is first order in the oxygen pressure and other kinetic parameters are fitted to the measured data one obtains the following rate expression:

$$
\frac{d X}{d t}=3268 \mathrm{~min}^{-1} \cdot P a^{-1} \cdot \exp \left(\frac{-125 \mathrm{~kJ} / \mathrm{mol}}{R T}\right)(1-X)^{3 / 2} p_{O_{2}}
$$

Where $X$ is the degree of carbon conversion, $R$ is the gas constant, $T$ is the temperature and $p_{O_{2}}$ is the partial pressure of oxygen. The reaction order in the carbon conversion is usually interpreted in terms of the development in reactant surface area with carbon consumption $(2 / 3$ for shrinking spheres, 1 for a fully porous solid). A reaction order above one implies that the surface area increases with increasing consumption, which is usually not realistic. However, in the present case, where the degree of conversion is increased through increasing temperature, the in situ TEM studies illustrate that the very important Ag-soot interfacial area can increase at higher temperature as a result of silver's mobility, so the high reaction order in the carbon conversion is to some extent consistent with the observed behavior of the catalyst. Figure 10Figure 10 shows the measured carbon oxidation rates in TPO experiments at two different partial pressures of oxygen, namely $10335 \mathrm{~Pa}$ (as used in the other TPO experiments) and $296 \mathrm{~Pa}$ (representing the pressure used in the in situ TEM experiments) as well as the predicted rate profiles using the fitted rate expression. The figure shows that the same rate expression can be used to provide a reasonable description of the behavior at both the two oxygen pressures, and since the occurrence of the oxidation in the in situ TEM experiments agrees well with 
TPO experiments in $296 \mathrm{~Pa}$ oxygen it seems that the temperature differences between TEM and TPO experiments (compare Table 1 and Table 2) can be attributed mainly to the pressure difference between the two methods.

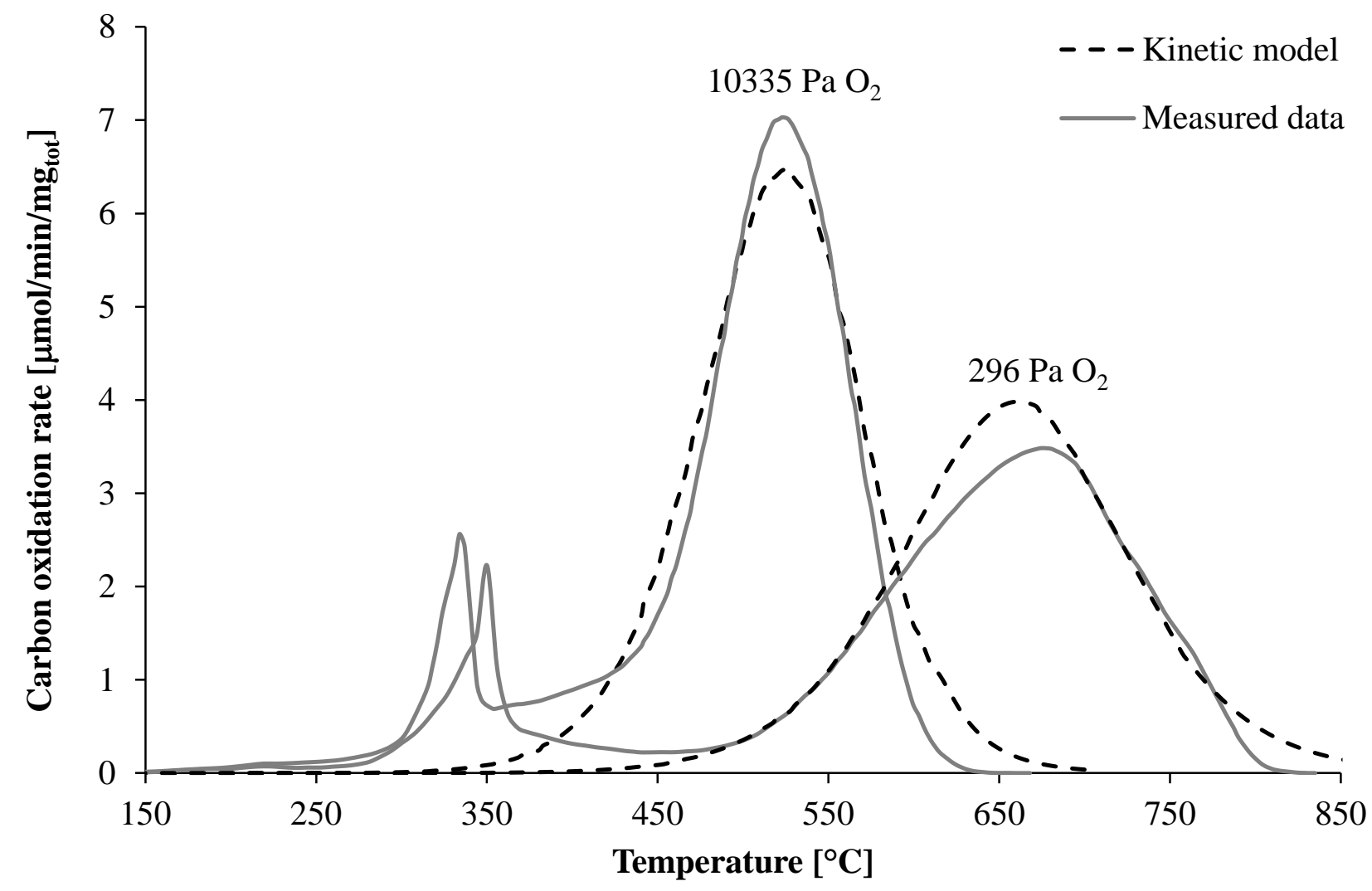

Figure 10 The rate of carbon oxidation (normalized by the total, initial mass of carbon) during TPO in loose contact with silver at two different oxygen partial pressures. Solid lines represent the experimental data and dashed lines the theoretical profiles calculated according to the presented kinetic model. Experimental conditions: Soot:silver $=1: 5 \mathrm{wt}: \mathrm{wt}, \mathrm{T}$ ramp $=11^{\circ} \mathrm{C} / \mathrm{min}, 10335 \mathrm{~Pa} \mathrm{O}_{2}$ $=1 \mathrm{NL} / \mathrm{min}, 10.2 \mathrm{vol} \% \mathrm{O}_{2}$ in $\mathrm{N}_{2}, 296 \mathrm{~Pa} \mathrm{O}_{2}=1 \mathrm{NL} / \mathrm{min} 2960 \mathrm{ppmv} \mathrm{O}_{2}$ in $\mathrm{N}_{2}$.

\section{Conclusion}

In this study the catalytic behavior of metallic silver nanoparticles during soot oxidation was studied by means of TPO experiments carried out in a flow reactor and in an environmental transmission electron microscope. Soot:silver mixtures in a ratio 5:1 wt:wt showed different catalytic activity depending on the contact condition between soot and catalyst, which was determined by the preparation method. Crushing soot and silver together in a mortar (tight contact condition) resulted 
in a much finer dispersion of silver particles within the soot cake as compared to soot:silver mixtures prepared by simply stirring the two powders with a spatula (loose contact condition). Flow reactor TPO experiments showed that silver in both contact types is able to achieve a relatively low carbon oxidation temperature. In a flow of $10 \mathrm{vol} \% \mathrm{O}_{2}$ in $\mathrm{N}_{2}$ the maximal carbon oxidation rate of noncatalytic oxidation occurred at a temperature of $654{ }^{\circ} \mathrm{C}$, whereas the maximal oxidation rate occurred at significantly lower temperatures in loose contact $\left(520^{\circ} \mathrm{C}\right)$ or particularly in tight contact $\left(450{ }^{\circ} \mathrm{C}\right)$ with Ag nanoparticles. The considerable activity of silver in both contact conditions should at least in part be ascribed to the behavioral characteristics of the silver particles, particularly their significant mobility, responsible for ensuring the constant presence of a reactive carbon-silver-oxygen interface during oxidation. Mobility of silver was observed by in situ oxidation experiments in the ETEM. Attractive forces, possibly van der Waal forces, exist between the metal and carbon, and in an oxidizing atmosphere, where the carbon is oxidized at the catalyst/carbon interface and the reaction front thus moves, these attractive forces pull the silver particles along with the progressing reaction front and cause significant mobility of the catalyst particles. The relatively good loose contact activity of silver could be related to the fact that the high mobility of the silver helps to overcome the poor initial dispersion of the catalyst particles. Concerning the difference between loose and tight contact, the mobility was observed in ETEM experiments to be triggered at lower temperatures for mixtures in tight contact $\left(342-700{ }^{\circ} \mathrm{C}\right)$, compared to loose contact $\left(500-760{ }^{\circ} \mathrm{C}\right)$. The mobility is a process highly influenced by the balance between attractive forces connecting silver agglomerates to the porous soot matrix and the size of the silver agglomerates themselves, which dictates their internal cohesive energy. As an example an isolated silver particle is not restricted by an internal cohesive energy in the same way as a silver particle within a larger silver cluster, and the isolated particle can therefore be set in motion by the progressing reaction front at a lower temperature as observed in the ETEM experiments.

The high mobility of silver shown here is of importance for the understanding of silver catalysts used for soot oxidation and should also be of importance for other soot oxidation catalysts that could derive mobility from e.g. a low melting point, for example vanadium oxide.

\section{Acknowledgements}

Financial support from The Danish Council for Strategic Research (DSF) is gratefully acknowledged (Grant No. 2106-08-0039). The A. P. Møller and Chastine Mc-Kinney Møller Foundation is 
gratefully acknowledged for its contribution towards the establishment of the Center for Electron Nanoscopy at the Technical University of Denmark.

\section{References}

[1] Ris, C. US EPA health assessment for diesel engine exhaust: A review. Inhal. Toxicol. 2007; 19:229-239.

[2] Chameides, WL, Bergin, M. Soot takes center stage. Science 2002; 297:2214-2215.

[3] Kerr, RA. Soot is warming the world even more than thought. Science 2013; 339:382-382.

[4] Frank, B, Schuster, M, Schlögl, R, Su, DS. Emission of highly activated soot Particulate-The other side of the coin with modern diesel engines. Angew. Chem. Int. Ed. 2013; 52:2673-2677. [5] Kittelson, DB. Engines and nanoparticles: A review. J. Aerosol Sci. 1998; 29:575-588.

[6] Andreae, MO, Ramanathan, V. Climate's dark forcings. Science 2013; 340:280-281.

[7] Van Setten, BAAL, Makkee, M, Moulijn, JA. Science and technology of catalytic diesel particulate filters. Catal. Rev. Sci. Eng. 2001; 43:489-564.

[8] Adler, J. Ceramic diesel particulate filters. Int. J. Appl. Ceram. Technol. 2005; 2:429-439.

[9] Stamatelos, AM. A review of the effect of particulate traps on the efficiency of vehicle diesel engines. Energy Convs. Mgmt. 1997; 38:83-99.

[10] Southward, BWL, Basso, S. An investigation into the $\mathrm{NO}_{2}$-decoupling of catalyst to soot contact and its implications for catalysed DPF performance. SAE paper 2008-01-0481, 2008. [11] Neeft, J, Makkee, M, Moulijn, JA. Metal oxides as catalysts for the oxidation of soot. Chem. Eng. J. 1996; 64:295-302.

[12] Konstandopoulos, AG, Lorentzou, S, Pagkoura, C, Ohno, K, Ogyu, K, Oya, T. Sustained soot oxidation in catalytically coated filters. SAE paper 2007-01-1950, 2007.

[13] Konstandopoulos, AG, Papaioannou, E. Update on the science and technology of diesel particulate filters. Kona 2008; 26:36-65.

[14] Konstandopolous, A, Papaioannou, E, Zarvalis, D, Skopa, S, Baltzopoulou, P, Kladopoulou, E, et al. Catalytic filter systems with direct and indirect soot oxidation activity. SAE paper 2005-010670, 2005.

[15] Kumar, PA, Tanwar, MD, Bensaid, S, Russo, N, Fino, D. Soot combustion improvement in diesel particulate filters catalyzed with ceria nanofibers. Chem. Eng. J. 2012; 207-208:258-266. 
[16] Kameya, Y, Lee, KO. Soot cake oxidation on a diesel particulate filter: Environmental scanning electron microscopy observation and thermogravimetric analysis. Energy Technol. 2013; 1:695-701.

[17] Liang, Q, Wu, X, Wu, X, Weng, D. Role of surface area in oxygen storage capacity of ceriazirconia as soot combustion catalyst. Catal. Lett. 2007; 119:265-270.

[18] Shimizu, K, Kawachi, H, Satsuma, A. Study of active sites and mechanism for soot oxidation by silver-loaded ceria catalyst. Appl. Catal. B 2010; 96:169-175.

[19] Christensen, JM, Deiana, D, Grunwaldt, J-D, Jensen, AD. Ceria prepared by flame spray pyrolysis as an efficient catalyst for oxidation of diesel soot. Catal. Lett 2014; 144:1661-1666. [20] Christensen, JM, Grunwaldt, J-D, Jensen, AD. Importance of the oxygen bond strength for catalytic activity in soot oxidation, submitted.

[21] Böcklein, S, Günther, S, Wintterlin, J. High-Pressure scanning tunneling microscopy of a silver surface during catalytic formation of ethylene oxide. Angew. Chem. Int. Ed. 2013; 52:5518-5521. [22] Campbell, CT. Atomic and molecular oxygen adsorption on Ag (111). Surf. Sci. 1985; 157:4360.

[23] Kayama, T, Yamazaki, K, Shinjoh, H. Nanostructured ceria- silver synthesized in a one-pot redox reaction catalyzes carbon oxidation. J. Am. Chem. Soc. 2010; 132:13154-13155.

[24] Yamazaki, K, Kayama, T, Dong, F, Shinjoh, H. A mechanistic study on soot oxidation over $\mathrm{CeO}_{2}-\mathrm{Ag}$ catalyst with 'rice-ball' morphology. J. Catal. 2011; 282:289-298.

[25] Corro, G, Pal, U, Ayala, E, Vidal, E. Diesel soot oxidation over silver-loaded $\mathrm{SiO}_{2}$ catalysts. Catal. Today 2013; 212:63-69.

[26] Ikeue, K, Kobayashi, S, Machida, M. Catalytic soot oxidation by $\mathrm{Ag} / \mathrm{BaCeO}_{3}$ having tolerance to $\mathrm{SO}_{2}$ poisoning. J. Ceram. Soc. Jap. 2009; 117:1153-1157.

[27] Machida, M, Murata, Y, Kishikawa, K, Zhang, D, Ikeue, K. On the reasons for high activity of $\mathrm{CeO}_{2}$ catalyst for soot oxidation. Chem. Mater. 2008; 20:4489-4494.

[28] Aneggi, E, Llorca, J, de Leitenburg, C, Dolcetti, G, Trovarelli, A. Soot combustion over silversupported catalysts. Appl. Catal. B 2009; 91:489-498.

[29] Shigapov, A, Dubkov, A, Ukropec, R, Carberry, B, Graham, G, Chun, W, McCabe, R. Development of PGM-free catalysts for automotive applications. Kin. Catal. 2008; 49:756-764. [30] Shimizu, K, Katagiri, M, Satokawa, S, Satsuma, A. Sintering-resistant and self-regenerative properties of $\mathrm{Ag} / \mathrm{SnO}_{2}$ catalyst for soot oxidation. Appl. Catal. B 2011; 108:39-46. 
[31] Lim, C-B, Kusaba, H, Einaga, H, Teraoka, Y. Catalytic performance of supported precious metal catalysts for the combustion of diesel particulate matter. Catal. Today. 2011; 175:106-111. [32] Yamazaki, K, Sakakibara, Y, Dong, F, Shinjoh, H. The remote oxidation of soot separated by ash deposits via silver-ceria composite catalysts. Appl. Catal. A 2014; 476:113-120.

[33] Haneda, M, Towata, A. Catalytic performance of supported Ag nano-particles prepared by liquid phase chemical reduction for soot oxidation. Catal. Today. 2015; 242:351-356.

[34] Im, J, Lee, CM, Coates, JT. Comparison of two reference black carbons using a planar PCB as a model sorbate. Chemosphere 2008; 71:621-628.

[35] Braun, A, Mun, BS, Huggins, FE, Huffman, GP. Carbon speciation of diesel exhaust and urban particulate matter NIST standard reference materials with C (1s) NEXAFS spectroscopy. Environ. Sci. Technol. 2007; 41:173-178.

[36] Gustafsson, Ö, Bucheli, TD, Kukulska, Z, Andersson, M, Largeau, C, Rouzaud, J-N, Reddy, CM, Eglinton, TI. Evaluation of a protocol for the quantification of black carbon in sediments. Global Biogeochem. Cycles 2001; 15:881-890.

[37] Hansen, TW, Wagner, JB, Dunin-Borkowski, RE. Aberration corrected and monochromated environmental transmission electron microscopy: Challenges and prospects for materials science. Mater Sci. Technol. 2010; 26:1338-1344.

[38] Shen, J, Ziaei-Azad, H, Semagina, N. Is it always necessary to remove a metal nanoparticle stabilizer before catalysis?. J. Mol. Catal. A 2014; 391:36-40.

[39] Czanderna, AW. Isosteric heat of adsorption of oxygen on silver. J. Vac. Sci. Technol. 1977; $14: 408-411$.

[40] Ostrovskii, VE. The chemisorption of oxygen on group IB metals and their surface oxidation. Russ. Chem. Rev. 1974; 43:921-932.

[41] Engelhardt, HA, Menzel, D. Adsorption of oxygen on silver single crystal surfaces. Surf. Sci. 1976; 57:591-618.

[42] Nørskov, JK, Bligaard, T, Logadottir, A, Bahn, S, Hansen, LB, Bollinger, M, et al. Universality in heterogeneous catalysis. J. Catal. 2002; 209:275-278.

[43] Baker, RTK, France, JA, Rouse, L, Waite, RJ. Catalytic oxidation of graphite by platinum and palladium. J. Catal. 1976; 41:22-29.

[44] Hennig, GR. Catalytic oxidation of graphite. J. Inorg. Nucl. Chem. 1962; 24:1129-1137.

[45] Booth, TJ, Pizzocchero, F, Andersen, H, Hansen, TW, Wagner, JB, Jinschek, JR, et al. Discrete dynamics of nanoparticle channelling in suspended graphene. Nanolett. 2011; 11:2689-2692. 
[46] Pizzocchero, F, Vanin, M, Kling, J, Hansen, TW, Jacobsen, KW, Bøggild, P, et al. Graphene edges dictate the morphology of nanoparticles during catalytic channeling. J. Phys. Chem. C 2014; 118:4296-4302. 